\title{
Trends in HCV prevalence, risk factors and distribution of viral genotypes in injecting drug users: findings from two cross-sectional studies
}

\author{
M. L. A. OLIVEIRA ${ }^{1 *}$, C. F. T. YOSHIDA ${ }^{2}$, P. R. TELLES ${ }^{3}$, M. A. HACKER ${ }^{4}$, \\ S. A. N. OLIVEIRA ${ }^{2}$, J. C. MIGUEL ${ }^{2}$, K. M. R. Do Ó ${ }^{2}$ AND F. I. BASTOS ${ }^{5}$ \\ ${ }^{1}$ National Reference Laboratory for Viral Hepatitis and National Reference Laboratory for Influenza and \\ Exanthematic Diseases, Oswaldo Cruz Institute, Oswaldo Cruz Foundation, Rio de Janeiro, Brazil \\ ${ }^{2}$ National Reference Laboratory for Viral Hepatitis, Oswaldo Cruz Institute, Oswaldo Cruz Foundation, \\ Rio de Janeiro, Brazil \\ ${ }^{3}$ Center for Drug Abuse Treatment and Research (NEPAD), State University of Rio de Janeiro, Rio de Janeiro, \\ Brazil \\ ${ }^{4}$ Laboratory of Leprosy, Oswaldo Cruz Institute, Oswaldo Cruz Foundation, Rio de Janeiro, Brazil \\ ${ }^{5}$ Department of Health Information, Center for Information on Science and Technology, Oswaldo Cruz \\ Foundation, Rio de Janeiro, Brazil
}

(Accepted 10 December 2008; first published online 15 January 2009)

\section{SUMMARY}

In the last decade, a declining prevalence of $\mathrm{HCV}$ infection has been described in injecting drug users (IDUs) in different countries. This study is the first to assess temporal trends in druginjecting patterns, HCV infection rates and viral genotype distribution in 770 Brazilian IDUs, recruited by two cross-sectional studies (1994-1997 and 1999-2001). A substantial decline in the prevalence of HCV infection was found over the years ( $75 \%$ in $1994 v s .20 .6 \%$ in 2001, $P<0.001)$ that may be a consequence of the significant reduction in the overall frequencies of drug injection and needle-sharing, as well as the participation of IDUs in initiatives aimed at reducing drug-related harm. No trend was found in terms of viral genotype distribution. Despite the favourable scenario, preventive measures must be maintained, especially in vulnerable subgroups such as young or new injectors, where risky behaviours through direct and indirect sharing practices remain common.

Key words: Hepatitis C, infectious disease epidemiology, injecting drug use, molecular epidemiology.

\section{INTRODUCTION}

Hepatitis $\mathrm{C}$ virus (HCV) infection is a global health issue and one of the leading causes of hepatocarcinoma. According to the World Health Organization (WHO), about $3 \%$ of the world's population is

* Author for correspondence: Dr Maria de Lourdes Aguiar Oliveira, Laboratório de Referência Nacional para Influenza e Doenças Exantemáticas, Laboratório de Vírus Respiratórios e do Sarampo, Instituto Oswaldo Cruz, Fundação Oswaldo Cruz, Av. Brasil, 4365, Manguinhos, Rio de Janeiro, CEP 21040-360, Brazil. (Email: mlaoliveira@fiocruz.br) infected by $\mathrm{HCV}$, with 3-4 million people infected each year [1]. Of these, about $60-85 \%$ will develop chronic hepatitis [2].

HCV epidemiology has improved over time in highand middle-income countries, mainly due to the increase in blood transfusion safety and improvements in health-care conditions. Currently, injecting drug use is the main mode of viral transmission, accounting for more than $60 \%$ of prevalent cases in Europe [3].

$\mathrm{HCV}$ is efficiently transmitted through exposure to infected blood. Hence, the common practice of 
injecting drug users (IDUs) in risky behaviours such as direct and indirect sharing of injection paraphernalia [4-7] favours a fast and extensive viral transmission within IDU networks. Cohort studies have shown that HCV seroconversion can be observed within a short period from first drug injection, varying between a few months to about 3 years $[8,9]$. In such a way, a high frequency of HCV infection (up to $98.0 \%$ ) [10-12] has been reported in these subjects, with an apparent peak in 1980-1990 [12]. In the last decade, a declining prevalence of $\mathrm{HCV}$ infection has been observed in IDUs from different settings in Australia, USA and Europe [12-17]. However, infection rates still remain fairly high.

$\mathrm{HCV}$ is classified into six major genotypes and several subtypes [18], which have distinct geographical patterns and responses to antiviral therapy [19]. Moreover, viral genotypes have been associated with different routes of transmission [20]. Recently, a changing pattern of $\mathrm{HCV}$ genotype distribution has been described in Europe, with increasing frequencies of HCV 1a, 3a and 4 infections (the latter especially in IDUs) [3]. Shifts in viral genotype distribution are relevant, since they can positively or negatively impact on the future burden of disease.

The aim of this study is to investigate trends over time of drug-injecting patterns, HCV infection rates and viral genotype distribution in IDUs from Rio de Janeiro. Although pivotal to the implementation of harm-reduction policies, such information is not available for the Brazilian drug scene.

\section{STUDIED POPULATION AND METHODS}

\section{Population}

The population under analysis is composed of 770 IDUs from Rio de Janeiro, recruited by two crosssectional surveys. The first sample $(n=164)$ was part of an epidemiological multicentre study on human immunodeficiency virus (HIV) and risk behaviours in IDUs, carried out in five Brazilian cities (Projeto Brasil) from 1994 to 1997. The second was part of the WHO Drug Injection Study, Phase II $(n=606)$, carried out from 1999 to 2001. IDUs were recruited from the 'drug scene' (public places, nightclubs, bars) in Rio de Janeiro, as previously described [11, 21, 22].

In both studies IDUs were interviewed using a structured questionnaire eliciting sociodemographic information in addition to drug-injecting and sexual behaviours and practices. The questionnaire adopted in the first survey (1994-1997) was based on the instrument used in the WHO 'Multi-city Study on Drug Injecting and Risk of HIV Infection' [23]. In the second survey, the questionnaire was standardized by the WHO and comprised similar and supplementary questions to those included in the first WHO multicentre study [22].

After signing an informed consent, volunteers were interviewed and asked to donate $30 \mathrm{ml}$ of blood for further testing. All interviewees received pre- and post-test counselling. HCV RNA-positive IDUs were referred to the network of Reference Public Hospitals for Viral Hepatitis C of Rio de Janeiro. HBV vaccination was available at no cost for those who agreed to be vaccinated. The studies were approved by the Oswaldo Cruz Foundation's Institutional Review Board, as well as by local human subjects protection committees and the WHO, where applicable.

\section{Laboratory methods}

$\mathrm{HCV}$ antibodies were detected by a commercial immunoassay (UBI HCV EIA 4.0, Beijing United Inc., China). Initially reactive samples were retested in duplicate and the final result was given based on concordance between at least two of the three replicates.

Viral RNA was extracted using QIAamp ${ }^{\circledR}$ Viral RNA extraction kit (Qiagen GmbH, Germany). Detection of 5'-NCR HCV RNA was performed as previously described [24]. For NS5b, a one-step PCR was performed using the SuperScript ${ }^{\mathrm{TM}}$ III One-Step RT-PCR system with Platinum ${ }^{\circledR}$ Taq High Fidelity (Invitrogen Corp., USA). Briefly, $9 \mu 1$ RNA was added to a $25 \mu \mathrm{l}$ final mixture containing $10 \mathrm{pm}$ of each primer S1 and AS1, 2x reaction buffer and 1.0 U Taq polymerase. Thermocycling conditions consisted of 1 cycle of $42{ }^{\circ} \mathrm{C}$ for $45 \mathrm{~min}$; followed by 1 cycle of $95^{\circ} \mathrm{C}$ for $4 \mathrm{~min}$ and 40 cycles of $95^{\circ} \mathrm{C}$ for $20 \mathrm{~s}, 54{ }^{\circ} \mathrm{C}$ for $30 \mathrm{~s}$, and $72{ }^{\circ} \mathrm{C}$ for $1 \mathrm{~min}$. A final extension cycle of $72{ }^{\circ} \mathrm{C}$ for $10 \mathrm{~min}$ was achieved. For nested PCR, $1 \cdot 0 \mu 1$ of first-round amplification product was used. The primers for the first and nested PCR and the nested PCR protocol were used according to Chen \& Weck [25].

The amplified DNA products were sequenced in both sense and antisense directions using the Big Dye Sequencing kit version 3.1 (Applied Biosystems, USA) and were analysed with the ABI 3730 automated DNA sequencer. Primers used for sequencing 
were the same as for the nested PCR. The 5'-UTR and NS5b sequences spanned nucleotide positions 49-287 and 8277-8606, respectively (both numbered as in Kuiken et al. [26]; reference sequence H77AF009606). The Clustal X program was used for DNA alignment.

\section{Phylogenetic analysis}

Phylogenetic analysis was conducted using MEGA version 4 [27]. Phylogenetic trees were constructed using the Neighbour-Joining method [28], with bootstrap re-sampling (1000 replicates) [29]. The evolutionary distances were computed using the Maximum Composite Likelihood method [30] and were expressed as the number of base substitutions per site. $\mathrm{HCV}$ sequences were classified into genotypes, according to Simmonds et al. [18].

The accession numbers of reference and IDU sequences used in the present study were as follows: 1a (AF009606), 1b (M58335), 1c (AY051292), 2a (AF169004), 2b (AF238486), 2c (D50409), 3a (AF046866), 3b (D49374), 4a (Y11604), 5a (Y13184), 6a (Y12083), 6b (D84262), and IDUs EU678672 to EU678744 for 5'-UT region; 1a (AF009606), 1b (U45476), 1c (AY051292), 2a (AF169004), 2b (AF238486), 3a (D28917), 3b (D49374); 4a (Y11604), 5a (Y13184), 6a (Y12083), 6b (D84262), and IDUs EU747741 to EU747787 for the NS5b region, respectively.

\section{Data analysis}

Statistical analyses were performed using SPSS for Windows version 10.0 (SPSS Inc., USA). For bivariate analyses $\chi^{2}$ tests were used, except for continuous variables, for which $t$ tests were employed. Results were regarded as significant when $P<0 \cdot 05$. Trends on $\mathrm{HCV}$ infection and injecting risk practices were assessed using logistic regression. In these analyses, HCV was set as the dependent variable, whereas the year of interview (sample collection, reference category: 1994) or duration of injecting drug use (reference category: 0-2 years of injection) were the covariates of interest. Additional analyses took needle-sharing as the dependent variable and the year of sample collection as the covariate of interest (reference category: 1994). Reported $P$ values are referred to bivariate logistic models. Finally, for frequency analyses of HCV genotypes, year of first injection was used as a proxy of infection year.

\section{RESULTS}

Comparison of socio-demographic features, drug-injecting and sexual behaviours and practices and HCV infection in IDUs, 1994-2001

The socio-demographic features, the patterns of druginjecting and sexual behaviours, as well as the prevalence of $\mathrm{HCV}$ infection and viral genotypes from both studies are shown in Table 1. Duration of injecting drug use (expressed as years of injecting) and year of first drug injection were significantly different in the studies $(P<0 \cdot 001)$. In the second survey, almost half the sample were short-term IDUs, while in the first investigation about $70 \%$ were long-term IDUs. On the other hand, figures were similar for mean age, mean age of first injection, educational background, marital and residential status. The higher proportion of male IDUs in the later study suggested a temporal downturn in the number of females who inject drugs.

A significant decrease in the frequency of prison reports $(73.7 \%$ vs. $43.2 \%, P<0.001)$ was observed, possibly due to the reduction in the number of IDUs engaged in illegal activities, e.g. drug dealing and prostitution. Nevertheless, needle-sharing in imprisoned IDUs was significantly more practised, when both investigations were compared $(7 \cdot 8 \%$ vs. $70 \cdot 3 \%$, $P<0 \cdot 001)$.

Regarding drug-use behaviours and practices, cocaine was the drug of choice for IDUs, while other drugs played a negligible role in Rio de Janeiro's drug scene. Over time, significant reductions in the overall frequencies of injecting and needle-sharing, key determinants of blood-borne infections were observed. This changing behavioural pattern could partially explain the temporal decline in $\mathrm{HCV}$ prevalence (64.2\% vs. 16.8\%, in 1994-1997 and 1999-2001 periods, respectively, $P<0 \cdot 001)$.

Whatever is their sexual orientation or kind of partnership (with principal or casual partners or clients), $40-70 \%$ of IDUs reported unsafe sex, with increasing trends perceived in IDUs who reported casual partners $(42.9-68.4 \%, P<0.001)$ and declining tendencies in those who mentioned sexual intercourse with clients $(69 \cdot 5 \%$ vs. $39 \cdot 4 \%, P<$ $0 \cdot 001)$.

Finally, while a reduction in the number of subjects receiving treatment for drug abuse was seen $(69.8 \%$ vs. $31.5 \%, P<0.001)$, an increase in participation in needle-exchange programmes was observed over time $(0-30 \cdot 9 \%, P<0 \cdot 001)$. 
Table 1. Main socio-demographic features, drug use and sexual behaviours and practices and HCV infections among injecting drug users (IDUs) from Rio de Janeiro, assessed in two cross-sectional surveys, 1994-2001

\begin{tabular}{|c|c|c|c|}
\hline Variables & $\begin{array}{l}\text { Projeto Brasil } \\
1994-1997 \\
(n=164)(\%)\end{array}$ & $\begin{array}{l}\text { WHO Phase II study } \\
1999-2001 \\
(n=606)(\%)\end{array}$ & $P$ value \\
\hline \multicolumn{4}{|l|}{ Sociodemographic data } \\
\hline Gender (male) & $135(84 \cdot 4)$ & $554(91 \cdot 4)$ & $0 \cdot 001$ \\
\hline \multicolumn{4}{|l|}{ Education } \\
\hline Illiterate & $2(1 \cdot 3)$ & $18(3 \cdot 0)$ & $0 \cdot 571$ \\
\hline $1-8$ years & $62(40 \cdot 3)$ & $261(42 \cdot 9)$ & \\
\hline $9-12$ years & $59(38 \cdot 3)$ & $221(36 \cdot 3)$ & \\
\hline$>12$ years & $31(20 \cdot 1)$ & $108(17 \cdot 8)$ & \\
\hline Marital status (single) & $107(69 \cdot 0)$ & $391(64 \cdot 3)$ & $0 \cdot 157$ \\
\hline Residence (owned or rented house, flat or apartment)* & $60(39 \cdot 7)$ & $192(31 \cdot 6)$ & $0 \cdot 081$ \\
\hline Source of income & & & $<0 \cdot 001$ \\
\hline $\begin{array}{l}\text { Informal, benefits, student financial aid, } \\
\text { received income from someone else }\end{array}$ & $92(61 \cdot 3)$ & $497(86 \cdot 0)$ & \\
\hline Permanent job & $39(26 \cdot 0)$ & $65(11 \cdot 2)$ & \\
\hline Illegal activities & $19(12 \cdot 7)$ & $16(2 \cdot 8)$ & \\
\hline Ever been in prison $\dagger$ & $115(73 \cdot 7)$ & $251(43 \cdot 2)$ & $<0 \cdot 001$ \\
\hline Needle-sharing while imprisoned $\ddagger$ & $9(7 \cdot 8) \dagger$ & $45(70 \cdot 3) \$$ & $<0 \cdot 001$ \\
\hline \multicolumn{4}{|l|}{ Drug-use behaviours and practices } \\
\hline \multicolumn{4}{|l|}{ Main injected drugs* } \\
\hline Speedball & $5(3 \cdot 2)$ & $2(0 \cdot 8)$ & $0 \cdot 090$ \\
\hline Heroine & $12(7 \cdot 7)$ & $8(2 \cdot 9)$ & $0 \cdot 002$ \\
\hline Cocaine & $152(94 \cdot 4)$ & $263(97 \cdot 8)$ & $0 \cdot 060$ \\
\hline Methamphetamines & $43(27 \cdot 7)$ & $14(5 \cdot 1)$ & $<0 \cdot 001$ \\
\hline Frequency of injection ( $\geqslant 1$ time a week $)^{*}$ & $48(78 \cdot 7)$ & $150(55 \cdot 1)$ & $0 \cdot 001$ \\
\hline Needle-sharing* & $95(65 \cdot 5)$ & $100(36 \cdot 8)$ & $<0 \cdot 001$ \\
\hline Participation in needle-exchange programmes* & 0 & $79(30 \cdot 9)$ & $<0 \cdot 001$ \\
\hline Ever received treatment for drug abuse & $109(69 \cdot 8)$ & $174(31 \cdot 5)$ & $<0 \cdot 001$ \\
\hline $\begin{array}{l}\text { Frequency of short-term injecting drug use } \\
\text { (injecting drugs for } \leqslant 6 \text { years) }\end{array}$ & $37(24 \cdot 7)$ & $300(49 \cdot 3)$ & $<0 \cdot 001$ \\
\hline \multicolumn{4}{|l|}{ Sexual behaviours } \\
\hline $\begin{array}{l}\text { Never used condom with principal partners } \\
\text { of the opposite sex* }\end{array}$ & $53(58 \cdot 9)$ & $218(63 \cdot 2)$ & $0 \cdot 264$ \\
\hline Never used condom with casual partners of the opposite sex* & $39(42 \cdot 9)$ & $255(68 \cdot 4)$ & $<0 \cdot 001$ \\
\hline Never used condom with clients of the opposite sex* & $57(69 \cdot 5)$ & $28(39 \cdot 4)$ & $<0 \cdot 001$ \\
\hline Never used condom, male-to-male sex* & $45(57 \cdot 7)$ & $50(49 \cdot 0)$ & $0 \cdot 158$ \\
\hline \multicolumn{4}{|l|}{$\mathrm{HCV}$ infection } \\
\hline HCV prevalence & $106(64 \cdot 2)$ & $102(16 \cdot 8)$ & $<0 \cdot 001$ \\
\hline \multicolumn{4}{|l|}{ HCV subtypes } \\
\hline 1a & $8(23 \cdot 5)$ & $24(32 \cdot 9)$ & $0 \cdot 505$ \\
\hline $1 b$ & $12(35 \cdot 3)$ & $19(26 \cdot 0)$ & \\
\hline $3 \mathrm{a}$ & $14(41 \cdot 2)$ & $30(41 \cdot 1)$ & \\
\hline Continuous variables & Mean $( \pm$ S.D. $)$ & & \\
\hline Age (years) & $32 \cdot 3(7 \cdot 7)$ & $32 \cdot 2(9 \cdot 8)$ & $0 \cdot 153$ \\
\hline Age of first drug injection (years) & $19 \cdot 6(5 \cdot 3)$ & $19 \cdot 6(5 \cdot 5)$ & $0 \cdot 050$ \\
\hline Duration of injecting drug use (years) & $13 \cdot 6(8 \cdot 5)$ & $9 \cdot 6(8 \cdot 7)$ & $<0 \cdot 001$ \\
\hline Year of first injection & 1982 & 1990 & $<0 \cdot 001$ \\
\hline
\end{tabular}

* In the last 6 months, prior to the interview.

$\dagger$ In 116 IDUs who reported imprisonment.

\$ In 64 IDUs who shared needles and/or syringes while imprisoned.

'Needle-sharing' was defined as someone using syringes or needles together with or after someone else has used them. 'Duration of injecting drug use', expressed as years of injecting, was defined as the age of the interviewee at the interview date minus the age at the first injection. s.D., standard deviation. 


\section{HCV infection and temporal trends}

Temporal trends in the prevalence of HCV infection in IDUs are shown in Table 2. A substantial decline in HCV prevalence was found, from $75.0 \%$ in 1994 (reference category) to $20.6 \%$ in 2001 (OR 0.09 , $P<0 \cdot 001)$.

In both studies, longer duration of injecting drug use was identified as an independent predictor of $\mathrm{HCV}$ infection. In addition, needle-sharing in the last 6 months and imprisonment were also independently associated with viral infection in the first and second surveys, respectively [11, 21]. For this reason, tendencies in viral infection according to years of injecting drug use as temporal trends in the frequency of needlesharing were further assessed.

\section{Trends in needle-sharing}

Time trends in needle-sharing are shown in Table 2. Over time, a significant declining trend was observed in the overall frequency of needle-sharing $(P<0 \cdot 001)$.

Since direct sharing of injecting paraphernalia is one of the major routes of HCV transmission in IDUs and higher frequencies are usually found in novice injectors, the sample was stratified into short- and long-term IDUs. A declining temporal trend in the frequency of needle-sharing was seen in the latter $(75.0 \%$ in 1994 vs. $44.4 \%$ in 2001, $P<0.001)$. However, the same was not true for short-term injectors, in whom the frequency of needle-sharing remained high $(\geqslant 40.0 \%)$ over the years, with no discernible tendency $(P=0 \cdot 363)$.

\section{HCV infection and duration of injecting drug use}

Prevalence of $\mathrm{HCV}$ infection according to years of drug injecting is shown in Table 3. A significant increasing trend in $\mathrm{HCV}$ prevalence according to years of injecting was found in the combined sample (two studies), as well as for each study separately. Of those who injected drugs for up to 2 years (reference category), the prevalence of HCV infection was $13 \cdot 2 \%$. In the pooled sample, those injecting for $>10$ years were about four times more likely to be $\mathrm{HCV}$ infected when compared to the reference category (OR $4 \cdot 4,95 \% \mathrm{CI}$ $2 \cdot 5-7 \cdot 7)$.

In the first period (1994-1997), HCV prevalence was $33 \cdot 3 \%$ in the reference category vs. $70 \cdot 2 \%$ in those injecting for $>10$ years. Similar figures for the second study were $11.3 \%$ and $28.4 \%$, respectively.

\section{HCV genotypes}

A total of $160(76.9 \%)$ anti-HCV-positive samples were submitted for RT-PCR to detect 5'-UTR HCV RNA. For the remaining samples, sera volume was not enough to proceed to viral RNA extraction and additional testing. Positive HCV RNA 5'-UTR samples were further submitted to NS5b region testing and only $45.5 \%$ showed detectable HCV RNA. In this way, DNA sequencing was performed in a total of 107 and 51 samples for 5'-UTR and NS5b regions, respectively. Genotype distribution was similar in both surveys $(P=0 \cdot 505)$ (Table 1$)$, with a slightly higher overall prevalence of genotype $3 \mathrm{a}$ infections. When both studies were compared, a shift from HCV $1 \mathrm{~b}$ towards subtype 1a infections was observed $(P=0 \cdot 385)$.

Because of the young age at first drug injection (which leads to the assumption that a previous HCV infection is unlikely) and since $\mathrm{HCV}$ infection occurs in the early years of their IDU career [8,9], the year of first injection was used as a proxy of year of infection. HCV 1a (10\%), HCV 1b (50\%) and HCV 3a (40\%) were already seen in IDUs who started injecting drugs during the early 1960 s.

Although HCV $1 \mathrm{~b}$ were the most prevalent infections in former years, a decreasing prevalence was observed over time $(32 \%, 34 \%, 18 \%$ and $25 \%$ in the 1970s, 1980s, 1990s and 2000, respectively). Conversely, subtype 1a infections appear to be on the rise, reaching an apparent peak in the 1980s (37.5\%) and remaining stable thereafter $(25 \%$ in the 1990 s and $37.5 \%$ in 2000). Subtype 3 a infections were the most prevalent in the 1970s (40\%) and 1990s (57.1\%).

\section{DISCUSSION}

In the present study, trends over time in infection rates, genotype distribution and injecting risk behaviours and practices associated with $\mathrm{HCV}$ infection were assessed for IDUs from Rio de Janeiro. To our knowledge, this information was not available for the Brazilian drug scene despite it being critical for the design and tailoring of prevention and harmreduction strategies.

However, some limitations must be taken into account. First, despite the efforts to obtain a representative sample of Rio de Janeiro's drug scene, findings cannot be generalized to the IDU population, the size of which is effectively unknown. Second, the prevalence of $\mathrm{HCV}$ infection was found to be significantly 
Table 2. Trends in HCV infection and needle-sharing in injecting drug users (IDUs) from Rio de Janeiro, Brazil, 1994-2001

\begin{tabular}{|c|c|c|c|c|c|c|c|c|c|c|c|c|c|c|c|c|}
\hline \multirow[b]{3}{*}{ Year } & & & & & \multicolumn{12}{|c|}{ Needle-sharing } \\
\hline & \multicolumn{4}{|c|}{$\mathrm{HCV}$ infection } & \multicolumn{4}{|c|}{ Combined sample } & \multicolumn{4}{|c|}{ Short-term injectors } & \multicolumn{4}{|c|}{ Long-term injectors } \\
\hline & $n^{*}$ & $\%$ & OR & $95 \% \mathrm{CI}$ & $n^{*}$ & $\%$ & OR & $95 \% \mathrm{CI}$ & $n$ & $\%$ & OR & $95 \% \mathrm{CI}$ & $n$ & $\%$ & OR & $95 \% \mathrm{CI}$ \\
\hline $1994 \dagger$ & 16 & $75 \cdot 0$ & $1 \cdot 0$ & - & 16 & $68 \cdot 8$ & $1 \cdot 0$ & - & 4 & $50 \cdot 0$ & $1 \cdot 0$ & - & 12 & $75 \cdot 0$ & $1 \cdot 0$ & - \\
\hline $1995 \dagger$ & 43 & $81 \cdot 4$ & $1 \cdot 4$ & $0 \cdot 4-5 \cdot 7$ & 42 & $66 \cdot 7$ & $0 \cdot 9$ & $0 \cdot 2-3 \cdot 0$ & 12 & $66 \cdot 7$ & $2 \cdot 0$ & $0 \cdot 2-19 \cdot 9$ & 30 & $66 \cdot 7$ & $0 \cdot 6$ & $0 \cdot 1-3 \cdot 0$ \\
\hline $1996 \dagger$ & 71 & $56 \cdot 3$ & $0 \cdot 4$ & $0 \cdot 1-1 \cdot 4$ & 66 & $65 \cdot 2$ & $0 \cdot 8$ & $0 \cdot 3-2 \cdot 7$ & 17 & $52 \cdot 9$ & $1 \cdot 1$ & $0 \cdot 1-9 \cdot 9$ & 47 & $68 \cdot 1$ & $0 \cdot 7$ & $0 \cdot 2-3 \cdot 0$ \\
\hline $1997 \dagger$ & 34 & $52 \cdot 9$ & $0 \cdot 4$ & $0 \cdot 1-1 \cdot 4$ & 21 & $61 \cdot 9$ & $0 \cdot 7$ & $0 \cdot 2-2 \cdot 9$ & 3 & $66 \cdot 7$ & $2 \cdot 0$ & $0 \cdot 1-44 \cdot 3$ & 18 & $61 \cdot 1$ & $0 \cdot 5$ & $0 \cdot 1-2 \cdot 6$ \\
\hline $1999 \ddagger$ & 38 & $7 \cdot 9$ & $0 \cdot 03$ & $0 \cdot 006-0 \cdot 1$ & 24 & $25 \cdot 0$ & $0 \cdot 1$ & $0.04-0.6$ & 11 & $45 \cdot 5$ & $0 \cdot 8$ & $0 \cdot 1-8 \cdot 2$ & 13 & $7 \cdot 7$ & $0 \cdot 3$ & $0 \cdot 02-0 \cdot 3$ \\
\hline $2000 \%$ & 379 & $16 \cdot 1$ & 0.06 & $0 \cdot 02-0 \cdot 2$ & 206 & $35 \cdot 0$ & $0 \cdot 2$ & $0 \cdot 08-0 \cdot 7$ & 87 & $40 \cdot 2$ & $0 \cdot 7$ & $0 \cdot 1-5 \cdot 0$ & 119 & $31 \cdot 1$ & $0 \cdot 1$ & $0 \cdot 04-0.5$ \\
\hline $2001 \ddagger$ & 189 & $20 \cdot 6$ & 0.09 & $0 \cdot 03-0 \cdot 3$ & 42 & $52 \cdot 4$ & $0 \cdot 5$ & $0 \cdot 1-1 \cdot 7$ & 15 & $66 \cdot 7$ & $2 \cdot 0$ & $0 \cdot 2-18 \cdot 7$ & 27 & $44 \cdot 4$ & $0 \cdot 2$ & $0 \cdot 06-1 \cdot 2$ \\
\hline Total & & $27 \cdot 0$ & $(n=770)$ & & & $46 \cdot 8$ & $(n=415)$ & & & & $(n=149)$ & & & & $(n=264)$ & \\
\hline $\begin{array}{c}\text { Significance of } \\
\text { test for trend }\end{array}$ & & & $P<0.001$ & & & & $P<0.001$ & & & & $P=0.363$ & & & & $P<0.001$ & \\
\hline
\end{tabular}

OR, Odds ratio; CI, confidence interval.

* Total of IDUs per year.

$\dagger$ Projeto Brasil.

+. WHO Phase II study.

Short- and long-term IDUs are defined as those injecting drugs for $\leqslant 6$ years or $>6$ years, respectively [40]. 'Needle-sharing' is defined as someone using syringes or needles together with or after someone else has used them. Time trends were estimated by logistic regression, where HCV and needle-sharing were the dependent variables and reference category of independent variable year was set as 1994. 


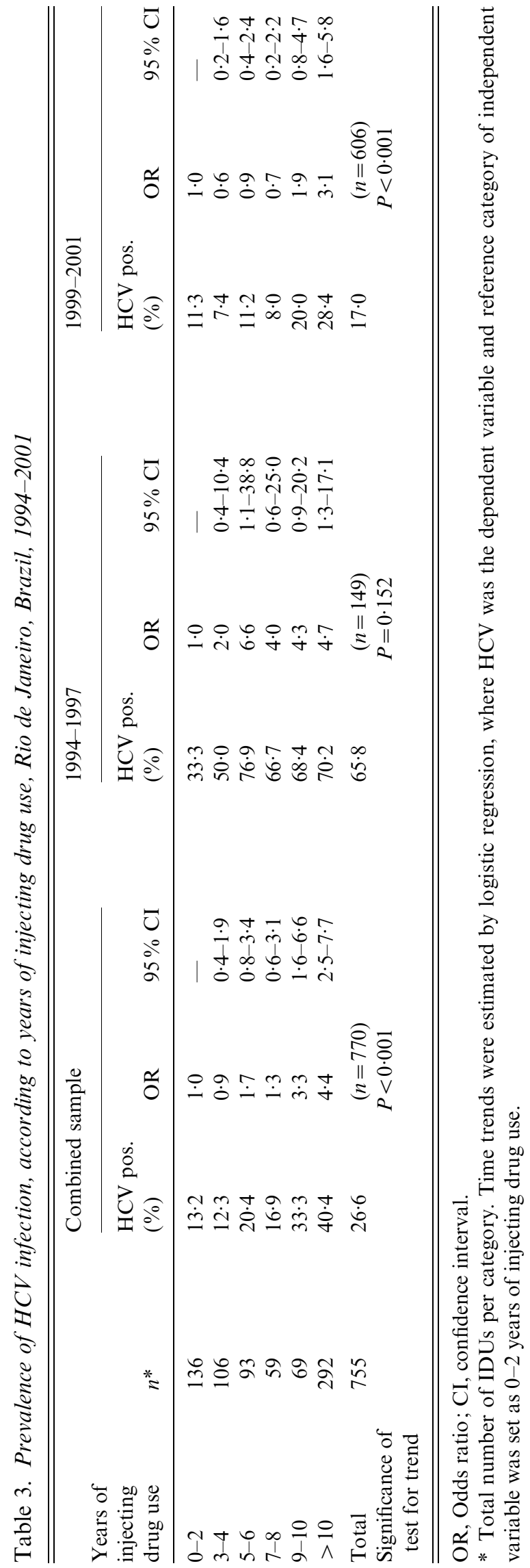

lower than expected when sample size was calculated for the second survey. Because small subsamples remained after stratification for some variables, we cannot rule out the lack of statistical power in the assessment of some associations. Furthermore, the pooled databank does not comprise all variables of interest, some of which were unavailable for the first investigation.

Over time, a significant smaller group of IDUs reported making a living from illegal activities, which may explain the decline of reported imprisonment from the first to the second survey. On the other hand, IDUs reported a high frequency of needle-sharing while imprisoned, an important route of viral transmission in prison inmates [31]. Stark et al. [32] studied the impact of a syringe exchange programme carried out in two prisons in Berlin. After 4 months, syringe sharing declined from $71.0 \%$ to $11.0 \%$ and to zero thereafter, illustrating the benefits of such programmes. Unfortunately, such initiatives do not exist in Brazilian jails.

Despite a still modest coverage, a significant increase in participation in syringe exchange programmes should be highlighted. During 1999-2001, IDUs integrated into such programmes were significantly less likely to be HCV infected than their counterparts (M. L. A. Oliveira, unpublished data). Although the impact of these programmes differs substantially in the prevention of HIV and HCV infections, they do make a contribution to the reduction of HCV prevalence in IDUs (see [33]). Hence, these programmes should not only be expanded but implemented in different settings, including prisons.

A declining incidence and prevalence of $\mathrm{HCV}$ infection in IDUs have been described in Australia [10, 13], USA [14, 16, 17] and Europe [7, 15, 34]. In agreement with these findings, a decreasing trend in the prevalence of $\mathrm{HCV}$ infection was also found in IDUs from Rio de Janeiro sampled by our two crosssectional studies $(75 \cdot 0 \%$ vs. $20 \cdot 6 \%)$. Besides other factors, such as network saturation and modifications in the drug-using scene [35], this trend over time could also be attributed to behavioural changes, such as the significant downturn in overall frequency of injecting and needle-sharing and the increasing participation of IDUs in initiatives aimed at reducing drug-related harm, particularly in the latter years.

Due to cumulative exposure, the frequency of $\mathrm{HCV}$ infection increases with duration of drug injection. Indeed, years of injecting drug use is the main predictor of viral infection in IDUs in Rio de Janeiro [11, 
21] and overseas $[9,10,36]$. The lower HCV prevalence found within the first years of injecting drug use reinforces the view that short-term IDUs should be considered as a target group for preventive measures, in order to curb HCV spread in susceptible new injectors.

On the other hand, young and short-term injectors are usually more involved in direct and indirect sharing of injecting paraphernalia than are long-term injectors $[6,21,36]$. Our data support these findings, since a significant temporal declining trend in the frequency of needle-sharing was observed in experienced IDUs, but not in new drug injectors. In a complementary view, IDUs were also involved in indirect sharing practices [21], behaviours which have also been associated with HCV transmission [4, 37].

Interestingly, a significantly lower rate of $\mathrm{HCV}$ RNA amplification for the NS5b region was obtained when samples collected in the first (1994-1997, $18 \cdot 1 \%)$ and second (1999-2001, 61.8\%) surveys were considered. If $5^{\prime}$-UTR status was unknown, it is likely that this low amplification rate could be due to storage conditions. Nevertheless, as both sets were positive for 5'-UTR HCV RNA and remained NS5b-negative after retesting, we cannot rule out the possibility of primer mismatch, due to heterologous sequences. Further testing comprising other HCV genome regions is necessary in order to elucidate these initial findings.

High frequencies of subtypes 1a and $3 \mathrm{a}$ are commonly found in IDUs compared to other exposure categories [3, 20]. The distribution of HCV genotypes found in the present study corroborates these findings. In our sample, HCV 1a, 1b and 3a were already established in the early 1960s if we consider the year of first drug injection as a proxy of infection year. Although far from being an ideal analysis, in the absence of additional information, the available data may be seen as providing a tentative picture. In our sample, HCV $1 \mathrm{~b}$ infections appear to be declining, whereas HCV 1a appear to be increasing over time. Coalescence studies on the epidemic history of HCV in European IDUs estimated a period of exponential growth of subtypes 1a and 3a infections during the last century. In those studies, whereas subtype 1a infections were on the rise, subtype $3 \mathrm{a}$ infections appeared to have reached a steady state [38, 39]. If subtype 1a becomes predominant in IDUs, an impact on disease burden can be expected, given the lower rates of virologically sustained response to current antiviral therapy in subjects infected by HCV 1 [19].
Taken together, these figures highlight that despite the favourable scenario of a declining prevalence of $\mathrm{HCV}$ infection, effective preventive measures must not be discontinued, especially in IDU subgroups such as young and short-term injectors, since risky behaviours like needle-sharing are not only common practice, but are also increasing. Such practices can support the maintenance of viral spread, even in a lower HCV background context.

Moreover, to successfully control HCV infections and other drug-related harms in these subjects, as foreseen by the Brazilian National Drug Policy, harm-reduction strategies must be tailored to these findings and expanded to effectively cover the demands of (injecting and non-injecting) drug users in Rio de Janeiro.

\section{ACKNOWLEDGEMENTS}

This paper is based on data from two cross-sectional studies: Projeto Brasil, a multicentre study carried out from 1994-1997 to estimate prevalence of HIV and viral hepatitis in five Brazilian cities and the WHO Drug Injection Study Phase II - a project, coordinated and sponsored by the World Health Organization and implemented by the WHO Phase II Drug Injection Collaborative Study Group. The authors alone are responsible for the views expressed in this paper, which do not necessarily represent those of the other investigators participating in the WHO Drug Injection Study Phase II nor the views or policy of the World Health Organization. The Brazilian component of the study was sponsored by WHO, as well as by the Coordenação Geral de Laboratórios, National Health Foundation, SVS, Ministry of Health, Brazil and Conselho Nacional de Desenvolvimento Científico e Tecnológico, CNPq, Grant no. 475668/03. We are grateful to Genomic Platform-DNA Sequencing (PDTIS-Fiocruz) for DNA sequencing of samples included in this study.

\section{DECLARATION OF INTEREST}

None.

\section{REFERENCES}

1. World Health Organization. Hepatitis C. Fact sheet no. 164. Revised October 2000 (http://www.who.int/ mediacentre/factsheets/fs164/en/print.html). Accessed 15 July 2008. 
2. National Institutes of Health Consensus Development Conference Statement. Management of hepatitis C 2002-10 June 2002. Hepatology 2002; 36: S3-S20.

3. Esteban JI, Sauleda S, Quer J. The changing epidemiology of hepatitis C virus infection in Europe. Journal of Hepatology 2008; 48: 148-162.

4. Thorpe LE, et al. Risk of hepatitis C virus infection among young adult injection drug users who share injection equipment. American Journal of Epidemiology 2002; 155: 645-653.

5. Hahn JA, et al. Hepatitis C virus seroconversion among young injection drug users: relationships and risks. Journal of Infectious Diseases 2002; 186: 15581564.

6. Thiede $\mathbf{H}$, et al. Prevalence and correlates of indirect sharing practices among young adult injection drug users in five U.S. cities. Drug and Alcohol Dependence 2007; 91 : S39-S47.

7. van den Berg CHSB, et al. Major decline of hepatitis C virus incidence rate over two decades in a cohort of injection drug users. European Journal of Epidemiology 2007; 22: 183-193.

8. Garfein RS, et al. Viral infections in short-term injection drug users: the prevalence of the hepatitis $\mathrm{C}$, hepatitis B, human immunodeficiency, and human T-lymphotropic viruses. American Journal of Public Health 1996; 86: 655-661.

9. Miller CL, et al. Opportunities for prevention: hepatitis $\mathrm{C}$ prevalence and incidence in a cohort of young injection drug users. Hepatology 2002; 36: 737-742.

10. Crofts N, et al. Epidemiology of hepatitis $C$ virus infection among injecting drug users in Australia. Journal of Epidemiology and Community Health 1997; 51: 692-697.

11. Oliveira ML, et al. Prevalence and risk factors for HBV, HCV and HDV infections among injecting drug users from Rio de Janeiro, Brazil. Brazilian Journal of Medical and Biological Research 1999; 32: 1107-1114.

12. Wiessing L, et al. Surveillance of hepatitis C infection among injecting drug users in the European Union. In: EMCDDA Scientific Monograph, Series no. 7. Luxembourg Office for Official Publications of the European Communities, 2004, pp. 91-130 (http:// www.emcdda.eu.int/index.cfm?fuseaction $=$ public. Content\&nNodeID $=6017 \&$ sLanguageISO $=\mathrm{EN}$ ) Accessed 15 July 2008.

13. MacDonald MA, et al. Hepatitis C virus antibody prevalence among injecting drug users at selected needle and syringe programs in Australia, 1995-1997. Collaboration of Australian NSPs. Medical Journal of Australia 2000; 172: 57-61.

14. Des Jarlais DC, et al. Reductions in hepatitis C virus and HIV infections among injecting drug users in New York City, 1990-2001. AIDS 2005; 19: $\mathrm{S} 20-\mathrm{S} 255$.

15. Muga R, et al. Significant reductions of HIV prevalence but not of hepatitis $C$ virus infections in injection drug users from metropolitan Barcelona: 1987-2001. Drug and Alcohol Dependence 2006; 82: S29-S33.
16. Tseng F, et al. Seroprevalence of hepatitis $\mathrm{C}$ virus and hepatitis B virus among San Francisco injection drug users, 1998 to 2000. Hepatology 2007; 46: 666-671.

17. Burt RD, et al. Trends in hepatitis B virus, hepatitis C virus, and human immunodeficiency virus prevalence, risk behaviors, and preventive measures among Seattle injection drug users aged 18-30 years, 1994-2004. Journal of Urban Health 2007; 84: 436-454.

18. Simmonds $\mathbf{P}$, et al. Classification of hepatitis $C$ virus into six major genotypes and a series of subtypes by phylogenetic analysis of NS-5 region. Journal of General Virology 1993; 74: 2391-2399.

19. Simmonds P. Genetic diversity and evolution of hepatitis C virus-15 years on. Journal of General Virology 2004; 85: 3173-3188.

20. Oliveira ML, et al. Distribution of HCV genotypes among different exposure categories in Brazil. Brazilian Journal of Medical and Biological Research 1999; 32: 279-282.

21. Oliveira ML, et al. 'The first shot': the context of first injection of illicit drugs, ongoing injecting practices, and hepatitis C infection in Rio de Janeiro, Brazil. Cadernos de Saúde Pública 2006; 22 : 861-870.

22. Des Jarlais DC, et al. WHO Phase II Drug Injection Collaborative Study Group. Using standardized methods for research on HIV and injecting drug use in developing/transitional countries: case study from the WHO Drug Injection Study Phase II. BMC Public Health 2006; 2(6): 54.

23. World Health Organization. Programme on substance abuse - Multi-city Study on Drug Injecting and Risk of HIV Infection. A report prepared on behalf of the WHO International Collaborative Group. Geneva, 1994.

24. de Oliveira JM, et al. Differences in HCV antibody patterns in haemodialysis patients infected with the same virus isolate. Journal of Medical Virology 2001; 63: $265-270$.

25. Chen Z, Weck K. Hepatitis C virus genotyping: interrogation of the $5^{\prime}$ untranslated region cannot accurately distinguish genotypes $1 \mathrm{a}$ and $1 \mathrm{~b}$, Journal of Clinical Microbiology 2002; 40: 3127-3134.

26. Kuiken $\mathbf{C}$, et al. A comprehensive system for consistent numbering of $\mathrm{HCV}$ sequences, proteins and epitopes. Hepatology 2006; 44: 1355-1361.

27. Tamura K, et al. MEGA4: Molecular Evolutionary Genetics Analysis (MEGA) software version 4.0. Molecular Biology and Evolution 2007; 24: 15961599.

28. Saitou N, Nei M. The neighbour-joining method: a new method for reconstructing phylogenetic trees. Molecular Biology and Evolution 1987; 4: 406-425.

29. Felsenstein J. Confidence limits on phylogenies: an approach using the bootstrap. Evolution 1985; 39: 783 791.

30. Tamura K, et al. Prospects for inferring very large phylogenies by using the neighbour-joining method. Proceedings of the National Academy of Sciences USA 2004; 101: 11030-11035. 
31. Stark K, et al. History of syringe sharing in prison and risk of hepatitis $\mathrm{B}$ virus, hepatitis $\mathrm{C}$ virus, and human immunodeficiency virus infection among injecting drug users in Berlin. International Journal of Epidemiology 1997; 26: 1359-1366.

32. Stark K, et al. A syringe exchange programme in prison as prevention strategy against HIV infection and hepatitis $\mathrm{B}$ and $\mathrm{C}$ in Berlin, Germany. Epidemiology and Infection 2006; 134: 814-819.

33. Strathdee SA, Patterson TL. Behavioral interventions for HIV-positive and HCV-positive drug users. AIDS and Behavior 2006; 10: 115-130.

34. Roy K, et al. Hepatitis $\mathrm{C}$ virus infection among injecting drug users in Scotland: a review of prevalence and incidence data and the methods used to generate them. Epidemiology and Infection 2007; 135: 433-442.

35. Bastos FI, et al. Is human immunodeficiency virus/acquired immunodeficiency syndrome decreasing among Brazilian injection drug users? Recent findings and how to interpret them. Memórias do Instituto Oswaldo Cruz 2005; 100: 91-96.

36. Buxton MB, et al. Association between injection practices and duration of injection among recently initiated injection drug users. Drug and Alcohol Dependence 2004; 75 : 177-183.

37. Lucidarme D, et al. Incidence and risk factors of $\mathrm{HCV}$ and HIV infections in a cohort of intravenous drug users in the North and East of France. Epidemiology and Infection 2004; 132: 699-708.

38. Pybus OG, et al. The hepatitis $\mathrm{C}$ virus epidemic among injecting drug users. Infection, Genetics and Evolution 2005; 5: 131-139.

39. Matheï C, et al. The epidemic history of hepatitis C among injecting drug users in Flanders, Belgium. Journal of Viral Hepatitis 2008; 15: 399-408.

40. Hacker MA, et al. The role of 'long-term' and 'new' injectors in a declining HIV/AIDS epidemic in Rio de Janeiro, Brazil. Substance Use \& Misuse 2005; 40: 99-123. 